\title{
Üniversite Öğrencilerinde Serbest Zaman Fiziksel Aktivite Kısıtlayıcıları İle Yaşamın Anlamı Arasındaki İlişki
}

\author{
The Relationship between Leisure Time Physical Activity Constraints and Meaning of Life \\ among University Students
}

Özgü INAL ${ }^{1}$, Sinem SALAR ${ }^{1}$

${ }^{1}$ Dr. Öğr. Üyesi, Trakya Üniversitesi, Sağlık Bilimleri Fakültesi, Ergoterapi Bölümü, Edirne/Merkez, Türkiye

\section{öz}

Amaç: Bu çalışma üniversite öğrencilerinde serbest zaman fiziksel aktivite kısıtlayıcıları ile yaşamın anlamı arasındaki ilişkinin incelenmesi amacıyla planlandı. Gereç ve Yöntem: Çalışmada; "Serbest Zaman Fiziksel Aktivite Kısıtlayıcıları (SZFA-K) Ölçeği" ve "Yaşamın Anlamı Ölçeği (YAÖ)" kullanıldı. Sonuçlar: Çalışmada, bireylerin tamamlayıcı özelliklerinin serbest zaman fiziksel aktivite kısıtlayıcıları ve yaşamın anlamı ile ilgili farklılıklar oluşturduğu belirlendi. Düzenli egzersiz alışkanlığı ve cinsiyetin iradenin 0,188 'ini açıkladığı $(R=0,433, R 2=0,188)$ saptandı. SZFA-K alt boyutlarından irade ile YAÖ alt boyutlarından mevcut anlam arasında zayıf düzeyde negatif yönde anlamlı korelasyon ( $r=-.21 ; p=.04)$ belirlendi. Diğer alt boyutlar (fiziksel algı, tesis, gelir, aile, yetenek algısı, zaman, sosyal çevre) arasında ise istatistiksel olarak anlamlı korelasyon saptanmadı. Tartışma: Çalışmanın sonuçları düzenli fiziksel egzersiz yapmanın serbest zaman fiziksel aktivite kısıtlayıcılarını azaltmakta önemli bir faktör olduğuna dikkat çekmiştir. Tersi olarak ise bireylerde düzenli egzersiz alışkanlığı geliştirmek açısından fiziksel aktivite kısıtlayıcılarına yönelik müdahalelerin yapılmasının yararlı olacağı düşünülmektedir. Ayrıca serbest zaman fiziksel aktivite katılımının artıııımasına yönelik programlar geliştirilirken; yapısal engeller kadar, irade gibi kişisel faktörler de dikkate alınmalıdır.

Anahtar kelimeler: Öğrenci; Serbest Zaman Aktiviteleri; Katııım

\section{ABSTRACT}

Purpose: The aim of this study was to investigate the relationship between leisure time physical activity constraints and meaning of life among university students. Material and Methods: In this study; Leisure Time Physical Activity Constraints (LTPA-C) Scale and Meaning In Life Questionnaire (MLQ) were used. Results: It was determined that the descriptive characteristics of individuals create differences about the leisure time physical activity constraints and the meaning of life. Regular exercise habit and gender explained 0.188 of the volition $(R=0,433, R 2=0,188)$. A weak significant negative correlation was found between with "volition" subscale of LTPA-C and "present meaning" subscale of MLQ ( $r=-.21 ; p=.04)$. There was no statistically significant correlation between other subscales (body perception, facilities, income, family, skill perception, time, society). Discussion: The results of the study pointed out that regular physical exercise is an important factor in decreasing leisure time physical activity constraints. On the other hand, it is thought that interventions aimed at physical activity constraints will be useful in order to develop a regular exercise habit in individuals. In addition, while developing programs to increase the participation of leisure time physical activity; it is important to focus on personal factors like volition as well as structural barriers.

Keywords: Student; Leisure Activities; Participation 
Yaşamın anlamı kavramı, son yıllarda kuvvetli yönlere ve olumlu özelliklere odaklanmanın artmasıyla birlikte, daha popüler hale gelmiştir. Yaşamdaki anlam, refah ve mental sağlığın göstergesi olarak kabul edilir, amaca yönelmeyi ifade eder ve her birey tarafından farklı şekillerde ifade edilir (Steger ve ark, 2006).

Serbest zaman; insanlara yaşamın değerli anlamlarını kazandıran, farkı şekillerde (psikolojik, ruhsal, sosyal ve/veya kültürel olarak) ortaya koyulan, önemli bir aktivite alanı olarak tanımlanmaktadır (Carruthers ve Hood, 2007; Hutchinson ve Nimrod, 2012; Iwasaki, Coyle, Shank ve ark, 2013; Watters, Pearce, Backman ve ark, 2013; Newman, Tay ve Diener, 2014). Daha genel olarak, anlamlı serbest zaman aktiviteleri, bireylerin genel bir anlam duygusu geliştirebilmelerini sağlar (Iwasaki, MacKay, Mactavish ve ark, 2006) ve bu aktivitelerin bireylerin refahı ve sağlığı için çok önemli olduğu düşünülmektedir (Turner, Chapman, McSherry ve ark, 2000).

Sağlık ve yaşam kalitesi açısından fiziksel aktivitelerin serbest zaman aktiviteleri içinde önemli bir yeri bulunmaktadır. Fiziksel aktivite, enerj harcamasını artıran iskelet kasları tarafından üretilen herhangi bir bedensel hareket olarak tanımlanır. Serbest zaman fiziksel aktivitesi ise, kişisel ilgilere ve intiyaçlara dayanarak, serbest zamanlarda katıım gösterilen aktivitelerin geniş bir tanımlayıcısıdır. Bu aktiviteler; yapılandırılmıs egzersiz programlarının yanı sıra yürüyüş, spor, dans gibi örnekleri içerebilir (Howley, 2001). Zorunluluklardan ve mecburiyetlerden kurtulabilmek genellikle serbest zamanın anahtar özelliğidir (Torkildsen, 2005) ve serbest zamanlarında fiziksel aktiviteye katılan bireylerin diğer bireylere oranla yaşam kalitelerinin daha yüksek olduğu rapor edilmektedir (Lustyk, 2004).

Fiziksel aktivitenin sağlığa katkıları bilinmesine rağmen, serbest zamanlarda gerçekleştirilen fiziksel aktivite seviyesi yetersizdir (Azevedo, Pavin Araújo, Reichert ve ark, 2007; Gomes, Matozinhos, Mendes ve ark, 2016). Dünya Sağlık Örgütü (DSÖ), yetişkinlerin \%23'nün ve okul çağı çocukların $\% 81$ 'nin yerince aktif olmadığını belirtmiş ve fiziksel olarak inaktif olmanın, bir yılda küresel olarak 3,2 milyon insanın ölümüne neden olan önemli risk faktörlerinden biri olduğunu bildirmiştir (World Health Organization, 2018). Yapılan çalışmalar, üniversite gençlerinin genel olarak serbest zaman etkinliklerine katıımakta güçlük çektiklerini ve öğrencilerin yalnızca \%18'inin yeterli düzeyde fiziksel aktivite yaptığını göstermektedir (Savcı ve ark, 2006; Özşaker, 2012).
Son otuz yıldır ele alınan "serbest zaman kısıtlayıcıları kavramı", bireylerin serbest zaman tercihlerinin daha iyi anlaşılmasına yardımcı olmaktadır (Godbey, Crawford ve Shen, 2010; Koçak, 2017). Serbest zaman kısıtlayıcıları, bireyin serbest zaman aktivitelerine katılımını engelleyen, aktivitelere tekrar katılım sayısını azaltan, zaman kaybına neden olan, aktivitelere katıma motivasyonunu azaltan, serbest zaman kullanımlarının avantajlarını ve aktivitelerden beklenen memnuniyeti azaltan faktörlerdir (Jackson, 2000; Son, Mowen ve Kerstetter, 2008; Kocak, 2017). Kısıtlayıcılar; "kişisel"( stres, depresyon, kaygı, beceri algısı, inanç ya da serbest zaman fiziksel aktivitelerin uygunluğuyla ilgili subjektif değerlendirmeleri) "kişilerarası"( cinsiyet rolleri, aile içi ilişkileri ve sosyal çevre ilişkileri) ve "yapısal" (finansal kaynak, iklim, iş yükü ve saatleri, imkân ve olanaklar) kısıtlayıcılar olmak üzere üç temel grupta incelenebilir (Crawford ve Godbey, 1987; Öcal, 2012).

Üniversite; bireyin şimdiki ve gelecekteki sağlığını belirleyecek bir yaşam tarzını geliştirmesi için ideal bir ortamdır (Molina-García, Castillo ve Pablos, 2009). Yaşamın anlamı kavramının incelenmesinin üniversite öğrencileri için büyük bir önem taşıdığı, yaşamda bir anlama sahip olmanın sağlık davranışları ile ilişkili olduğunu belirtilmiştir (Demirdağ ve Kalafat, 2015; Brassai, Piko ve Steger, 2011). Literatürde az sayıda çalışmada (Jim ve Andersen, 2007; Pinquart, 2002); fiziksel sağlığın daha iyi olmasının ve fiziksel işlevselliğin yaşamın anlamı kavramının yordayıcılarından olduğu belirtilmiştir. Bununla birlikte serbest zaman fiziksel aktivite kısıtlayıcıları ile yaşamın anlamı arasındaki ilişkiyi inceleyen bir çalışmaya rastlanmamıştır.

Çalışmamızın amacı, üniversite öğrencilerinde serbest zaman fiziksel aktivite kısıtlayıcıları ile yaşamın anlamı arasındaki ilişkiyi incelemek ve demografik özelliklere göre olası farklılıkları ortaya koymaktır. Elde edilecek bilgilerin, serbest zaman kısıtlayıcıları konusunda planlanacak müdahalelerde yol gösterici olması beklenmektedir.

\section{GEREÇ VE YÖNTEM}

Çalışma 18-25 yaş arası, Sağlık Bilimleri Fakültesinde eğitim gören 97 öğrenci ile gerçekleştirildi. Çalışma için gerekli etik kurul izni Trakya Üniversitesi Sosyal ve Beşeri Bilimler Araştırmaları Etik Kurulu'ndan alındı (Karar no: 11/19). Çalışma Helsinki Deklarasyonuna uygun olarak yürütüldü ve katıımcılardan yazılı onam formu alındı. 


\section{Veri Toplama Araçları}

Çalışmada araştırma ekibi tarafından oluşturulan demografik bilgi formu kullanılarak öğrencilerin demografik bilgileri kaydedildi. Öğrencilerin serbest zaman fiziksel aktivite kısıtlayıcılarını ölçmek için, Öcal (Öcal, 2012) tarafından geliştirilen "Serbest Zaman Fiziksel Aktivite Kısıtlayıcıları" (SZFA-K) Ölçeği kullanıldı. Ölçek 38 madde ve 8 boyuttan oluşmakta ve 6"lı likert tipindedir. Alt boyutlar; "fiziksel algı", "tesis", "gelir", "aile”, "yetenek algısı", "zaman", "irade" ve "sosyal çevre" dir. Ölçekte yüksek puan alınması, kısıtlayıcının yüksek yoğunluğunu, şiddetini ve baskısını ifade eder. Öğrencilerde yaşamın anlamını değerlendirmek için ise Türkçe geçerlik ve güvenirliği yapılmış olan Yaşamın Anlamı Ölçeği (YAÖ) kullanıldı (Akın ve Taş, 2015; Steger ve ark, 2006). Ölçek; 7’li likert tipi bir ölçme aracı olup 10 maddeden ve iki alt boyuttan (mevcut anlam ve aranan anlam) oluşmaktadır. Ölçeğin alt boyutundan alınan puanın yüksek olması, alt boyuta ait özelliğin kişide yaşam anlamına sahip olma ya da yaşamın anlamını arama düzeyinin yüksek olduğunu ifade etmektedir.

\section{İstatistiksel Analiz}

İstatistiksel değerlendirme, IBM Corp. Released 2010. IBM SPSS Statistics for Windows, Version 22.0. Armonk, NY: IBM Corp. Ve TURCOSA (Turcosa Analytics Ltd Co, Turkey, www.turcosa.com.tr) istatistik yazılımlarında gerçekleştirilmiştir. Ölçülebilen verilerin normal dağılıma uygunlukları tek örnek Shapiro Wilk testi ile bakıldıktan sonra normal dağılıma uymayan verilerin değerlendirilmesinde Mann Whitney $U$ testi ve Kruskal Wallis varyans analizi ve Post Hoc Dunn testi kullanılmıştır. Değişkenler arasındaki ilişkinin değerlendirilmesinde Spearman Rho korelasyon analizi yapılmıştır. Korelasyon değeri; 0.30-0.40 arası zayıf orta derecede, $0.40-0.60$ orta derecede, 0.60-0.70 iyi derecede, 0.70-0.75 çok iyi derecede korelasyon olarak alınmıştır. Egzersiz alışkanlığı, zaman ve yetenek algısı alt ölçek puanları bağımlı değişken olarak alındığında; bağımsız değişkenlerin bağımlı değişken üzerindeki ilişkisinin düzeyini ortaya koymak için Stepwise regresyon analizi yapıldı. Tanımlayıcı istatistikler olarak aritmetik

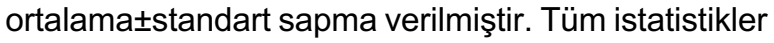
için anlamlılık sınırı $p<0.05$ olarak seçilmiştir.

\section{SONUÇLAR}

Çalışma Sağlık Bilimleri Fakültesi'nde eğitim gören 97 (76 kadın, 21 erkek) öğrenci ile tamamlandı. Çalışmaya dahil edilen öğrencilerin 9'u 1. sınıf, 32'si 2. sınıf, 11 'i 3. sınıf ve 45 'i 4. sınıftı. Öğrencilerin 58'i düzenli egzersiz yapıyordu.

Bireylerin tanımlayıcı özelliklerine göre SZFA-K ve YAÖ alt testleri tanımlayıcı istatistikleri Tablo 1'de yer almaktadır.

Çalışmada; SZFA-K ve YAÖ alt testleri bakımından bireylerin tanımlayıcı özelliklerine göre karşılaştırmaları incelendiğinde; kız öğrencilerin erkek öğrencilere kıyasla serbest zaman fiziksel aktivite kısıtlayıcılarını (irade, sosyal çevre ve zaman) ( $r=-3.54, p=<0.01 ; r=-2.00, p=0.04 ; r=-2.32$, $p=0.02)$ daha yüksek algıladıkları görülmektedir (Tablo 2).

Bireylerin SZFA-K ve YAÖ alt testleri arasındaki ilişki incelendiğinde; SZFA-K alt boyutlarından irade ile YAÖ alt boyutlarından mevcut anlam arasında zayıf düzeyde negatif yönde anlamlı korelasyon ( $r=-$ $.21 ; p=.04$ ) belirlendi (Tablo 3 ).

Çalışmada bireylerin tanımlayıcı özelliklerinin SZFA-K ve YAÖ alt testlerini yordayıp yordamadığına Stepwise Regresyon Analizi ile bakılmıştır. Yapılan analiz sonucunda düzenli egzersiz alışkanlığı ve cinsiyetin iradenin 0,188 'ini açıkladığı $(R=0,433, R 2=0,188)$ ve irade puanında kadınların erkeklere göre 3,10 birimlik bir artış, egzersiz yapmayanların da yapanlara göre 2,82 birimlik bir artışa neden olduğu söylenebilir. Egzersiz yapmayanların da yapanlara göre zaman alt ölçeği puanında 1,73 birimlik bir artışa neden olduğu söylenebilir $(\mathrm{R}=.246, \quad \mathrm{R} 2=.060)$. Yine egzersiz yapmayanların da yapanlara göre yetenek algısı alt ölçeği puanında 1,99 birimlik bir artışa neden olduğu söylenebilir ( $R=.241, \mathrm{R} 2=.058)$. 
Tablo 1. Bireylerin Tanımlayıcı Özelliklerine Göre SZFZ-K ve YAÖ Alt Testleri Tanımlayıcı İstatistikleri Tanımlayıcı Özellikler Mean (SD)

\begin{tabular}{|c|c|c|c|c|c|c|c|c|c|c|c|}
\hline & & Fiziksel algı & Tesis & Gelir & Aile & Yetenek algısı & Zaman & İrade & Sosyal Çevre & Mevcut anlam & Aranan anlam \\
\hline \multirow[b]{2}{*}{ Cinsiyet } & kadın & $10.76 \pm 0.52$ & $21.59 \pm 0.87$ & $15.78 \pm 0.81$ & $7.14 \pm 0.41$ & $9.40 \pm 0.48$ & $8.30 \pm 0.40$ & $11.10 \pm 0.54$ & $13.10 \pm 0.61$ & $22.26 \pm 0.61$ & $23.46 \pm 0.81$ \\
\hline & erkek & $9.04 \pm 0.76$ & $19.47 \pm 1.85$ & $14.71 \pm 1.79$ & $5.90 \pm 0.64$ & $7.09 \pm 0.59$ & $6.38 \pm 0.66$ & $7.23 \pm 0.86$ & $10.47 \pm 1.13$ & $23.47 \pm 1.18$ & $24.95 \pm 2.03$ \\
\hline \multirow{4}{*}{ Sinıf } & 1 & $8.66 \pm 1.14$ & $17.77 \pm 2.34$ & $10.33 \pm 1.99$ & $6.22 \pm 0.61$ & $8.11 \pm 1.16$ & $6.00 \pm 0.74$ & $8.55 \pm 1.83$ & $11.88 \pm 1.75$ & $23.55 \pm 2.26$ & $28.11 \pm 1.79$ \\
\hline & 2 & $12.21 \pm 1.02$ & $21.12 \pm 1.37$ & $15.65 \pm 1.14$ & $7.71 \pm 0.67$ & $10.03 \pm 0.84$ & $7.62 \pm 0.53$ & $11.50 \pm 0.89$ & $11.68 \pm 0.98$ & $22.50 \pm 1.00$ & $24.87 \pm 1.25$ \\
\hline & 3 & $10.09 \pm 1.18$ & $20.72 \pm 2.20$ & $17.09 \pm 2.54$ & $6.00 \pm 1.13$ & $8.18 \pm 0.86$ & $8.72 \pm 1.37$ & $11.72 \pm 1.60$ & $14.45 \pm 1.25$ & $20.90 \pm 1.47$ & $18.00 \pm 2.41$ \\
\hline & 4 & $9.51 \pm 0.46$ & $21.91 \pm 1.22$ & $16.15 \pm 1.14$ & $6.62 \pm 0.51$ & $8.44 \pm 0.57$ & $8.24 \pm 0.54$ & $9.37 \pm 0.62$ & $12.80 \pm 0.82$ & $22.73 \pm 0.74$ & $23.55 \pm 1.13$ \\
\hline \multirow{4}{*}{$\begin{array}{l}\text { Yaşanılan } \\
\text { yer }\end{array}$} & aile & $13.00 \pm 0.53$ & $24.14 \pm 2.32$ & $18.42 \pm 1.90$ & $9.57 \pm 1.25$ & $9.00 \pm 0.92$ & $8.57 \pm 1.21$ & $11.00 \pm 1.21$ & $13.71 \pm 1.42$ & $21.85 \pm 2.40$ & $23.28 \pm 2.04$ \\
\hline & arkadaş & $8.73 \pm 0.76$ & $18.61 \pm 1.45$ & $13.88 \pm 1.42$ & $6.65 \pm 0.83$ & $7.65 \pm 0.78$ & $6.38 \pm 0.63$ & $8.50 \pm 0.82$ & $10.96 \pm 1.03$ & $23.46 \pm 1.00$ & $24.11 \pm 1.68$ \\
\hline & yurt & $11.17 \pm 0.62$ & $22.24 \pm 1.07$ & $16.07 \pm 1.02$ & $6.84 \pm 0.42$ & $9.73 \pm 0.55$ & $8.45 \pm 0.45$ & $11.15 \pm 0.65$ & $13.12 \pm 0.74$ & $22.08 \pm 0.74$ & $23.59 \pm 0.96$ \\
\hline & yalnız & $7.57 \pm 0.86$ & $18.42 \pm 2.31$ & $14.71 \pm 2.39$ & $5.28 \pm 0.56$ & $6.71 \pm 1.40$ & $8.14 \pm 1.53$ & $8.85 \pm 2.39$ & $12.42 \pm 1.87$ & $23.28 \pm 1.04$ & $24.57 \pm 3.51$ \\
\hline Düzenli & evet & $9.81 \pm 0.57$ & $19.96 \pm 0.97$ & $14.79 \pm 0.91$ & $6.60 \pm 0.42$ & $8.10 \pm 0.51$ & $7.18 \pm 0.37$ & $8.89 \pm 0.61$ & $11.94 \pm 0.69$ & $22.68 \pm 0.74$ & $23.55 \pm 1.04$ \\
\hline egzersiz & hayır & $11.25 \pm 0.70$ & $22.87 \pm 1.30$ & $16.69 \pm 1.25$ & $7.28 \pm 0.62$ & $10.10 \pm 0.64$ & $8.92 \pm 0.64$ & $12.30 \pm 0.70$ & $13.41 \pm 0.87$ & $22.28 \pm 0.78$ & $24.12 \pm 1.14$ \\
\hline
\end{tabular}


Tablo 2. SZFA-K ve YAÖ Alt Testleri Bakımından Bireylerin Tanımlayıcı Özelliklerine Göre Karşılaştırmaları

\begin{tabular}{|c|c|c|c|c|c|c|c|c|c|c|c|c|c|c|c|c|c|c|c|c|}
\hline \multirow{2}{*}{$\begin{array}{l}\text { Tanımlayıcı } \\
\text { Özellikler }\end{array}$} & \multicolumn{2}{|c|}{ Fiziksel Algı } & \multicolumn{2}{|c|}{ İrade } & \multicolumn{2}{|c|}{ Tesis } & \multicolumn{2}{|c|}{ Gelir } & \multicolumn{2}{|c|}{ Sosyal Çevre } & \multicolumn{2}{|c|}{ Aile } & \multicolumn{2}{|c|}{ Zaman } & \multicolumn{2}{|c|}{ Yetenek Algısı } & \multicolumn{2}{|c|}{ Mevcut Anlam } & \multicolumn{2}{|c|}{ Aranan Anlam } \\
\hline & $z / x^{2}$ & $p$ & $z / x^{2}$ & $p$ & $z / x^{2}$ & $p$ & $z / x^{2}$ & $p$ & $z / x^{2}$ & $p$ & $z / x^{2}$ & $p$ & $z / x^{2}$ & $p$ & $z / x^{2}$ & $p$ & $z / x^{2}$ & $p$ & $z / x^{2}$ & $p$ \\
\hline SinIf & 5.62 & 0.13 & 5.67 & 0.13 & 1.40 & 0.71 & 5.20 & 0.16 & 2.50 & 0.48 & 3.63 & 0.30 & 2.85 & 0.41 & 2.68 & 0.44 & 1.70 & 0.64 & 8.66 & 0.03 \\
\hline $\begin{array}{c}\text { Yaşanılan } \\
\text { yer }^{* *}\end{array}$ & 5.58 & 0.01 & 7.17 & 0.07 & 6.10 & 0.10 & 3.04 & 0.38 & 2.90 & 0.40 & 8.54 & 0.03 & 8.23 & 0.04 & 8.40 & 0.03 & 2.04 & 0.56 & 0.92 & 0.82 \\
\hline $\begin{array}{l}\text { Düzenli } \\
\text { egzersiz } \\
\text { yapma* }\end{array}$ & -1.69 & 0.09 & -3.69 & $<0.01$ & -1.44 & 0.15 & -1.12 & 0.26 & -1.28 & 0.20 & -0.83 & 0.41 & -2.02 & 0.04 & -2.58 & 0.01 & -0.77 & 0.43 & -0.24 & 0.81 \\
\hline
\end{tabular}

*Mann-Whitney-U $\quad{ }^{* *} K r u s k a l$ Wallis ve Post Hoc Dunn testi $\quad p<0.05$ 
Tablo 3. Bireylerin SZFA-K ve YAÖ Alt Testleri Arasındaki İlişki

\begin{tabular}{lcccc}
\hline \multirow{2}{*}{ SZFA-K Alt Boyutları } & \multicolumn{3}{c}{ YAÖ Alt Boyutları } \\
\cline { 2 - 4 } & \multicolumn{1}{c}{ Mevcut anlam } & \multicolumn{2}{c}{ Aranan anlam } \\
\cline { 2 - 4 } Fiziksel algı & $r$ & 0.24 & $\mathrm{p}$ & 0.99 \\
\hline Tesis & -0.12 & 0.23 & 0.00 & 0.82 \\
\hline Gelir & -0.12 & 0.83 & -0.02 & 0.36 \\
\hline Aile & -0.02 & 0.35 & -0.09 & 0.17 \\
\hline Yetenek algısı & -0.09 & 0.46 & 0.14 & 0.82 \\
\hline Zaman & -0.08 & 0.23 & -0.07 & 0.47 \\
\hline İade & -0.12 & 0.04 & -0.05 & 0.61 \\
\hline Sosyal Çevre & -0.21 & 0.70 & -0.04 & 0.36
\end{tabular}

Speraman Korelasyon Analizi; $p<0.05$

\section{TARTIŞMA}

Bu çalışmada, serbest zaman fiziksel aktivite kısıtlayıcılarından irade faktörünün mevcut yaşamın anlamı ile ilişkisi olabileceği ve düzenli egzersiz yapmanın irade, zaman ve yetenek algısı ile ilgili kısıtlayıcılar üzerinde pozitif etkisi olduğu belirlendi.

İradenin fonksiyonu, temelde davranışı harekete geçirmektir ve fiziksel aktivite yapıp yapmamak veya yapmaya devam edip etmemek gibi konulardaki karar verme gücünü ifade etmektedir (Öcal, 2012). Serbest zaman ve fiziksel aktivite kısıtlayıcılarını inceleyen bazı çalışmalarda (Brown ve ark, 2006; Greaney ve ark, 2009), irade ve motivasyon eksikliğinin fiziksel aktivite katılımını engelleyen önemli faktörler olduğu belirtilmektedir. Çalışmamızda irade gibi kişisel bir faktörün, belirgin bir kısıtlayıcı olarak algılanmasa bile yaşamın anlamı ile ilişkili olabileceği gösterilmiştir. Kuramsal çerçeveden bakıldığında, irade faktörünün kapsadığı harekete geçme motivasyonu ile yaşam anlamının hedefe yönelme özelliği arasındaki ilişki tutarlı görünmektedir (Steger, 2012; Frankl, 2009). Ayrıca anlam arayışı, kişinin kişisel gelişimine ulaşamaması, çevresi üzerinde kontrol sahibi olamaması ya da kendini kabul etme becerisinin geliştirilememesi ile ilişkili olabilmektedir (Steger ve ark, 2008). Bu durumun kişiler tarafından anlamlı ve değerli bulunan, ilgileri ile örtüşen serbest zaman fiziksel aktiviteleriyle desteklenebileceği düşünülmektedir.

Çalışmamız; cinsiyet, sınıf, yaşanılan yer ve düzenli egzersiz yapma alışkanlığının serbest zaman fiziksel aktivite kısıtlayıcıları ve yaşamın anlamı ile ilgili farklılıklar oluşturduğuna dikkat çekmektedir. Kız öğrencilerin erkek öğrencilere kıyasla serbest zaman fiziksel aktivite kısıtlayıcılarını (irade, sosyal çevre ve zaman) daha yüksek algıladıkları görülmektedir. Haase ve ark. (2004) tarafından üniversite öğrencileri ile yapılan çalışmada erkek öğrencilerin tavsiye edilen seviyelerdeki serbest zaman fiziksel aktivite düzeyleri kadınlardan daha fazla bulunmuştur. Ülkemizde yapılan çalışmalar da kadınların hem fiziksel aktiviteye hem de serbest zaman aktivitelerine katılımda daha çok kısıtlayıcı algıladıklarını ortaya koymaktadır (Demir, 2005; Koca ve ark, 2009). Bu doğrultuda çalışmamızın bulguları, kız öğrenciler aleyhine irade/motivasyon (Demirel ve Harmandar, 2009; Güner, 2015), sosyal çevre (Koca ve ark, 2009; Demirel ve Harmander, 2009) ve zaman (Koca ve ark., 2009; Özşaker, 2012) kısıtlayıcılarını belirten literatürle örtüşmektedir.

Eğitim öğretim dönemine göre bakıldığında ise 2 . ve 3. sınıflardaki öğrencilerin kısıtlayıcıları daha fazla algıladığı ve özellikle 3. sınıfta yaşam anlamının belirgin şekilde kötüleştiği görülmektedir. Bazı çalışmalar (Calfas ve ark, 1994), üniversitede yıllara göre anlamlı bir fark olmadığını öne sürerken, bazı çalışmalar da (Huang, 2003) üniversite öğrencilerinin zaman içinde fiziksel olarak daha az aktif oldukları bildirilmiştir. Özellikle 2. ve 3. sınıflar üniversitede verilen mesleki eğitimin yoğunlaştığı zamanlara işaret etmekte ve öğrencilerin ders yüküyle birlikte aktivite-rol dengelerinin bozulduğu ve bu durum nedeni ile zaman yönetimi yapamadıklarını düşündürmektedir.

Araştırmacılar yaşam ortamının öğrencilerin fiziksel aktivitelerini etkilediğini bulmuşlardır (Keating ve ark., 2005). Dinger (1999), yurtlarda yaşayan öğrencilerin diğer öğrencilerden daha fazla fiziksel aktiviteye katıldığını belirtmiştir (Keating ve ark, 
2005; Dinger, 1999). Çalışmamızda genel olarak, yurtta yaşayan öğrencilerin ailesi ile yaşayan öğrencilere göre daha az ama yalnız yaşayan öğrencilere göre daha çok kısıtlayıcı algıladıklarını belirlenmiştir.

Çalışmamızda; düzenli egzersiz yapma ile irade, zaman ve yetenek algısı kısıtlayıcıları arasında negatif yönde bir ilişki belirlendi. Ek olarak düzenli egzersiz yapma alışkanlığı ve cinsiyetin, iradenin yordayıcısı olduğu saptandı. Literatürde egzersiz ya da spor yapmanın iradeyi güçlendiren bir faktör olduğuna dikkat çekilmiştir. Yapılan bir araştırmada (Saygılı ve ark, 2015), lisanslı olarak spor yapan bireylerin dışadönüklük (dürüst, kolay iletişim kurabilen, iyiliksever, samimi) ve sorumluluk (güçlü bir iradeye sahip, dakik, düzenli, kararlı,) kişilik özeliklerinin spor yapmayan bireylere göre daha iyi olduğu bulundu. Çalışmamızın bulguları da bu kapsamda egzersiz yapma alışkanlığının irade faktörü ile ilişkisine dikkat çekmektedir.

Çalışmamızın birtakım limitasyonları bulunmaktadır. Çalışmada serbest zaman fiziksel aktivite kolaylaştırıcılarının ve başa çıkma yöntemlerinin değerlendirilmemiş olması, serbest zaman katılımının bütüncül bir bakış açısıyla yorumlanmasını güçleştirmektedir. Ayrıca çalışma örnekleminin sadece bir üniversiteden alınmış olması sonuçların genellenebilirliğini etkilemektedir. Dolayısıyla sonuçların daha kapsamlı çalışmalarla desteklenmesi gerekmektedir.

Bu çalışmanın sonuçları göz önüne alındığında; düzenli egzersiz yapmayan bireylerde irade, zaman ve yetenek algısı kısıtlayıcılarının fazla olabileceği öngörülebilmektedir. Fiziksel egzersizi arttırmaya yönelik müdahalelerin bu faktörler üzerine yoğunlaştırılması gerektiği düşünülmektedir. Özellikle 2. ve 3. Sınıf öğrencilerine yönelik zaman yönetimi ve aktivite-rol dengesi eğitimleri verilmesi önerilmektedir. Ayrıca, aktiviteye katılım ve devamlılığın sağlanması açısından irade ilgili çalışmaların planlanması, yaşam amacına katkı verme potansiyeli açısından önemli görülmektedir.

\section{Kaynaklar}

Akın, A., \& Taş, İ. (2015). Yaşam anlamı ölçeği: geçerlik ve güvenirlik çalışması. Turkish Studies, 10(3), 27-36.

Azevedo, M. R., Pavin Araújo, C. L., Reichert, F. F., Siqueira, F. N, Cozzensa da Silva, M., \& Hallal, P. C. (2007). Gender differences in leisure-time physical activity. Int $J$ Public Health, 52(1), 8-15.

Brassai, L., Piko, B. F., \& Steger, M. F. (2011). Meaning in life: is it a protective factor for adolescents' psychological health? Int J Behav Med, 18(1), 44-51.
Brown, S. A., Huber, D., \& Bergman, A. (2006). A perceived benefits and barriers scale for strenuous physical activity in college students. Am J Health Promot, 21(2), 137-140.

Calfas, K. J., Sallis, J. F., Lovato, C. Y., \& Campbell, J. (1994). Physical activity and its determinants before and after college graduation. Med Exercise Nutr Health, 3, 323334.

Carruthers, C., \& Hood, C. D. (2007). Building a life of meaning through therapeutic recreation: the leisure and well-being model, part I. Ther Recreation J, 41(4), 276-297.

Crawford, D., \& Godbey, G. (1987). Reconceptualizing barriers to family leisure. Leis Sci, 9, 119-127.

Demir, C. (2005). Perceived significance of factors influencing leisure participation by gender: Implications from Turkey. Leisure, 29(1), 121-136.

Demirel, M., \& Harmandar, D. (2009). Üniversite öğrencilerinin rekreasyonel etkinliklere katılımlarında engel oluşturabilecek faktörlerin belirlenmesi. Uluslararası Insan Bilimleri Dergisi, 6(1), 838-846.

Demirdağ, S., \& Kalafat, S. (2015). Yaşamın Anlamı Ölçeği (YAÖ): Türkçeye uyarlama, geçerlik ve güvenirlik çalışması. Inönü Üniversitesi Eğitim Fakültesi Dergisi, 16(2), 83-95

Dinger, M. K. (1999). Physıcal Actıvity And Dietary Intake Among College Students. Am J Health Stud, 15(3).

Frankl, V. E. (1997). Insanın anlam arayışı. Ankara: Öteki Yayınevi.

Godbey, G., Crawford, D. W., \& Shen, X. S. (2010). Assessing hierarchical leisure constraints theory after two decades. $J$ Leis Res, 42(1), 111-134.

Gomes, C. S., Matozinhos, F. P., Mendes, L. L., Pessoa, M. C., \& Velasquez-Melendez, G. (2016). Physical and social environment are associated to leisure time physical activity in adult of a brazilian city: a cross-sectional study. Plos One, 11(2), 1-11.

Greaney, M. L., Less, F. D., White, A. A., Dayton, S. F., Riebe, D., Blissmer, B., ... \& Greene, G. W. (2009). College students' barriers and enablers for healthful weight management: a qualitative study. $J$ Nutr Educ Behav, 41(4), 281-286.

Güner, B. (2015). Kadınların spor ve serbest zaman etkinliklerine katılım sorunlarının değerlendirilmesi. Uluslararası Spor Bilimleri Dergisi, 1(1), 22-29.

Haase, A., Steptoe, A., Sallis, J. F., \& Wardle, J. (2004). Leisure-time physical activity in university students from 23 countries: associations with health beliefs, risk awareness, and national economic development. Preventive Medicine, 39(1), 182-190.

Howley, E. T. (2001). Type of activity: resistance, aerobic and leisure versus occupational physical activity. Med Sci Sports Exerc, 33(6), 364-369.

Huang, T. T. K., Harris, K. J., Lee, R. E., Nazir, N., Born, W., \& Kaur, H. (2003). Assessing overweight, obesity, diet, and physical activity in college students. $J \mathrm{Am}$ Coll Health, 52(2), 83-86.

Hutchinson, S. L., \& Nimrod, G. (2012). Leisure as a resource for successful aging by older adults with chronic health conditions. Int J Aging Hum Dev, 74(1), 41-65.

Iwasaki, Y., Coyle, C., Shank, J., Messina, E., \& Porter, H. (2013). Leisure-generated meanings and active living for persons with mental Ilness. Rehabil Couns Bull, 57(1), 46-56. 
Iwasaki, Y., MacKay, K., Mactavish, J., Ristock, J., \& Bartlett, J. (2006). Voices from the margins: Stress, active living, and leisure as a contributor to coping with stress. Leis Sci, 28(2), 163-180.

Jackson, E. L. (2000). Will research on leisure constraints still be relevant in the twenty-first century? J Leis Res, 32(1), 62-68.

Jim, H. S., \& Andersen, B. L. (2007). Meaning in life mediates the relationship between social and physical functioning and distress in cancer survivors. $\mathrm{Br} J$ Health Psychol, 12(3), 363-381.

Keating, X. D., Guan, J., Piñero, J. C., \& Bridges, D. M. (2005). A meta-analysis of college students' physical activity behaviors. J Am Coll Health, 54(2), 116-126.

Koca, C., Henderson, K. A., Asci, F. H., \& Bulgu, N. (2009). Constraints to leisure-time physical activity and negotiation strategies in Turkish women. Journal $J$ Leis Res, 41(2), 225-251.

Kocak, F. (2017). The relationship between leisure constraints, constraint negotiation strategies and facilitators with recreational sport activity participation of college students. Coll Stud J, 51(4), 491-497.

Lustyk, M. K. B., Widman, L., Paschane, A. A., \& Olson, K. C. (2004). Physical activity and quality of life: assessing the influence of activity frequency, intensity, volume, and motives. Behav Med, 30(3), 124-132.

Molina-García, J., Castillo, I., \& Pablos, C. (2009). Determinants of leisure-time physical activity and future intention to practice in Spanish college students. Span $J$ Psychol, 12(1), 128-137.

Newman, D. B., Tay, L., \& Diener, E. (2014). Leisure and subjective well-being: A model of psychological mechanisms as mediating factors. J Happiness Stud, 15(3), 555-578.

Öcal, K. (2012). Ölçek geliştirme: Serbest zaman fizikse aktivite kısıtlayıcıları (SZFA-K). Spor Bilimleri Dergisi, 23(2), 50-60.

Özşaker, M. (2012). Gençlerin serbest zaman aktivitelerine katılamama nedenleri üzerine bir inceleme. Selçuk Üniversitesi Beden Eğitimi ve Spor Bilim Dergisi, 14(1), 126-131.

Pinquart, M. (2002). Creating and maintaining purpose in life in old age: A meta-analysis. Ageing Int, 27(2), 90-114.

Saygılı, G., Emrah, A. T. A. Y., Eraslan, M., \& Hekim, M. (2015). Düzenli olarak spor yapan ve yapmayan öğrencilerin kişilik özellikleri ile akademik başarıları arasındaki ilişkinin incelenmesi. Kastamonu Eğitim Dergisi, 23(1), 161-170.

Savcı, F. D. S., Öztürk, U. F. M., \& Arıkan, F. D. H. (2006). Üniversite öğrencilerinin fiziksel aktivite düzeyleri. Türk Kardiyol Dern Arş, 34(3), 166-172.

Son, J. S., Mowen, A. J., Kerstetter, D. L. (2008). Testing alternative leisure constraint negotiation models: An extension of Hubbard and Manned's study. Leis Sci, 30(3), 198-216.

Steger, M. F. (2012). Making meaning in life. Psychol Inq, 23(4), 381-385.

Steger, M. F., Frazier, P., Oishi, S., Kaler, M. (2006). The meaning in life questionnaire: Assessing the presence of and search for meaning in life. J Couns Psychol, 53(1), 80.

Steger, M. F., Kashdan, T. B., Sullivan, B. A., \& Lorentz, D. (2008). Understanding the search for meaning in life:
Personality, cognitive style, and the dynamic between seeking and experiencing meaning. J Pers, 76(2), 199228.

Turner, H., Chapman, S., McSherry, A., Krishnagiri, S., \& Watts, J. (2000). Leisure assessment in occupational therapy: An exploratory study. Occup Ther Health Care, 12(2-3), 73-85.

Watters, A. M., Pearce, C., Backman, C. L., \& Suto, M. J. (2013). Occupational engagement and meaning: The experience of Ikebana practice. J Occup Sci, 20(3), 262277.

World Health Organization. (2018). Physical Activity. https://www.who.int/news-room/facts-inpictures/ detail/physical-activity (Erişim tarihi:22.07.2019)

Torkildsen, G. (2005). Leisure and Recreation Management, (Fifth edition). London: Routledge. 